\title{
Planning toward an Ontario cottage policy
}

REINER JAAKSON

Faculty of Forestry

University of Toronto

Toronto, Ont.
A 10-point plan is proposed as a debating target and the first step toward an Ontario cottage policy.
The Province of Ontario does not have a comprehensive cottage policy. Although certain policies exist which deal with the use of Crown Land for cottages, there is no general policy to assure that a socially just and an environmentally sound development takes place in areas used for seasonal recreation residences. Ontario has no cottage policy, and it urgently needs one.

Ownership of a cottage has become deeply rooted in the lifestyle of many families; it epitomizes the "good life". It is, however, ironical that several incongruencies shadow this strong adherence, or almost myth, associated with ownership of a cottage. These incongruencies expose some social inequities in Ontario, as well as on a national and a global scale.
Part of the Ontario population enjoys one of the more hedonic extravagances of highly developed, post-industrial societies: the ability of not only having fulfilled the prerequisites of a reasonably sound and comfortable shelter as a first, permanent abode, but the luxury of owning a second residence used largely or purely for leisure time and recreation activities. Concomitantly, another sector of Ontario society suffers in that it cannot afford even a decent primary residence, let alone a secondary one. Globally speaking, housing in Ontario is of a high standard, when compared to the relative costs, housing conditions, living densities, and services that exist in other parts of the world and, in fact, in other parts of Canada.

A question may very well be raised as to wheth-

\section{1/ Regional planning}

A cottage policy cannot be established in Ontario without first formulating policies for regional planning of cottage areas. Which areas of Ontario are developing most rapidly for cottaging? What are the forecasts for growth? How will new province-wide policies for regional development, transportation, and growth centres affect future cottage growth? Should Ontario intentionally steer cottage development to unused or underused areas, to ameliorate congestion elsewhere? These and many other questions loom formidably against the complex tapestry of the growth of the province.

One useful byproduct of the energy crisis has been that it introduced critical speculation about many heretofore unquestioned life habits. Some of this speculation has focused on that much -maligned ubiquity, the automobile. The cottage and the automobile are almost inseparable since, for the large majority of cottage owners transportation to the cottage is dependent on the family car. It is quite likely, however, that at least for some families, where the expense of maintaining a cottage already strains the budget, the prospect of increasingly more expensive private automobile travel may result in changing recreation activity styles. These changes may be from cottage use to more intensive use of public parks and other public recreation facilities close to urban centres. Public transportation to cottage areas, once quite important, may have to be reexamined within the novel context of the emergent view of what we consider to be appropriate uses of energy resources.

There is a need in Ontario for regional cottage development priority maps which would delineate the following policy guidelines. First, cottage areas that are over-used and where further development should be curtailed. Second, ecologically sensitive areas where development should be avoided, or where restrictions for development should be enforced. Third, public conflict areas where private cottage use conflicts with, or excludes, public use of resources. (Expropriation of some cottages in select areas may be necessary to allow the public to gain access to, and use of, certain lakes.) Fourth, growth areas for new cottage development. A hierarchy of cottage development-priority maps should be developed, delineating the above four categories on a broad province-wide basis, on a sub-regional basis, and on a local lake basis.

\section{2/ Environmental quality}

Environmental quality is perhaps one of the more critical issues, especially in ecologically sensitive areas such as the pre-Cambrian shield lakes. Complete protection of the biotic communities of lakes used for cottaging necessitates control measures of recreation activity, and possibly even suspension of the use of some recreation equipment, which would result in politically unpalatable public protest. It is tragic that the current popular concept of recreation is enlaced with an ingrained subscription to mechanical equipment, much of which is unwittingly designed to destroy our natural environment. The snowmobile, highspeed motorboat, and the all-terrainvehicle are examples of recreation fixtures which must be closely monitored. Only by channelling social values to a new mould can notions of recreation be amended to conform to activity patterns which may be harmoniously practised in the ecosys- tems which harbour recreation resources.

The provincial government needs to take immediate action to protect more strongly lake, littoral, and forest communities from environmental deterioration due to rapid cottage development and cottage generated recreation activity. The legislation that must be passed should be derived from a philosophy of "user penalty". The costs of maintaining, or of restoring, the quality of an area should be borne primarily by the users themselves. A lack of sufficiently strong legislation to control misuse and over-use is a poor excuse for allowing the costs of environmental maintenance to spread from those directly responsible, to those who have no vested interests in a locality and who, through devious means (the absence of public access points to the water, for example) may even be prevented from using an area. The public purse should not finance the concealment of private negligence.

\section{3/ Subdivision and development}

Ontario does not have concise legislation which standardizes the processes of land subdivision and of granting building permits; these processes are tortuously slow and involve a disarray of ministeries in their approval steps. By comparison, in some other provinces these development processes have been speeded up by means of special regulations. In Saskatchewan, for example, regulations passed under The Planning and Development Act, and The Department of the Environment Act, declare precisely the subdivision and building permit rules which everyone must adhere to.

The Ontario Economic Council's review of municipal planning in Ontario, entitled Subject to Approval, recommends that the designation "areas of 
er there actually is a need in Ontario for a cottage policy. It could be argued that the problem is being managed from a number of vantage points, and that results are being achieved in some quarters. However, what seems to be lacking is comprehensiveness of these independent attempts, and coordination of diverse efforts to assure that different lines of action converge at a mutually defined central goal. In this sense, a cottage policy in Ontario is needed and new local and regional planning measures called for.

Here, I categorize and evaluate some of the main problems associated with resource allocation for cottages in Ontario. The discussion, which is but one interpretation of a complex problem, should be used as a catalyst for innovative planning and as an idea source for future research. Although the province of Ontario is used as a case study, the rubrics apply equally well to the other provinces. Furthermore, whereas the jurisdiction for regional planning and resources management for cottages rests with the provinces, the larger problem is national in scope.

A ten-point plan toward an Ontario cottage po- licy is proposed. The ten categories are, of course, provisional and subject to discussion as to both their validity and their scope. They are presented as debating targets. Hopefully, if they are scrutinized, criticized, and contradicted, the first (albeit miniscule) step toward an Ontario cottage policy will have been embarked upon.

The Friday evening and Sunday night traffic tidal waves, to and from cottage regions in the recreation hinterland around large cities, are symptomatic of not only the culture of cottaging, but of urban lifestyles generally. The economy, especially employment, is still scheduled around a chronology which is rather archaic, often unnecessary, and increasingly more cumbersome.

One of the original rationales for the concentration of finance in the city core was to facilitate face to face contact for business transactions. ${ }^{2}$ Today, modern electronic and communications technology have largely removed the original rationale for the central business district. ${ }^{5}$ It may now be far more change" should be used where rapid development takes place, to allow municipalities to administer new control measures in addition to those of zoning and subdivision approval. The report $^{11}$ recommends that

development control power should replace zoning and site-plan agreements in (areas of change), and should cover matters normally regulated in those documents. Development control should consist of a statutory freeze on all development ... with development permission granted by council only after a case-by-case examination of proposals."

It is clear that many cottage areas are indeed experiencing very rapid change, either in the form of new de. velopment, or in the form of changing uses, or altered seasonality of use, of existing developments. Most cottage regions could, without dispute, be designated as "areas of change". The scope of planning in such rapidly growing areas must be broadened if environmental protection and development control are to be effective. For example, large-scale cottage subdivision should take place only in carefully monitored stages. Developers should be given performance standards which must be achieved before approval is given for the first stage of development, and for any subsequent expansion of development. Such performance standards could include the contribution by the developer toward the social infrastructure of an area (a grant for the organization and continued operation of a cottager association), or the provision for public facilities at a lake (boat launching site, public marina, day-use areas)

\section{4/ Carrying capacity}

Subdivision is acceptable only if the land and the water environments can accommodate new development. Vacant land in itself is not adequate testimony for there being sufficient room for new cottage subdivision. Lots sprout cottages, cottages spawn people, people seed activity - activity which may become an intolerable intrusion to an ecosystem and which may culminate in environmental deterioration. The burden of development may be light or heavy, and the ecological transformations may be reversible or irreversible, depending largely on the number of people who generate various activities, the intensity and the radius of activities, and the initial quality of the host environment where activities are performed.

As man becomes more civilized, the progressive technical sophistication of his equipment results in retrogressive abuse of the environment. The irony is that this need not be so. The same villain technology may also allow us to redeem our past environmental sins, and just possibly to absolve us of our future ones. On the one hand, technology is being abused; on the other hand, technology is not being harnessed to its full potential. The pit toilet and washboard of former times were a relatively light burden for the environment. Automatic dishwashers and washing machines spew nonbiodegradable pollutants into our water supply, and our swimming, boating, and wildlife-observation lakes. Today we are cleaner.... our environment is dirtier.

We have reached a state where we have to curb and voluntarily relinquish some of the frills of our civilization, in order to remain civilized.

How much development can a lake accommodate; how many cottages, people, cars, boats, and washing machines? Ideally, development in an area should be allowed only after summer and winter carrying capacity criteria have been determined. ${ }^{7}$ However, since it may take years to establish these criteria, there is an urgency, in areas where development takes place today, to monitor the environment carefully, in order not to surpass its inherent carrying capacity, whatever it may be. We do not want to spend a decade establishing scientifically accurate carrying capacity criteria, only to find that in many areas development in the meantime has already surpassed maximum acceptable levels.

An innovative concept, whereby over-use of cottaging lakes can be avoided and whereby no one user group displaces any other user group, has been formulated for the planning of regions of undeveloped lakes. This concept of private development in balance with public use may be described as a "mosaic" pattern of regional cottage planning. Its relationship to carrying capacity is discussed elsewhere. ${ }^{10}$

\section{5/ Zoning}

Zoning is generally accepted as an integral part of the management of urban environments. Activities which are considered not to be complementary are spatially segregated. However, outside the built-up urban and suburban milieu, zoning frequently is the prey to easy revision, possibly since in rural areas zones are more extensive and tend to be regarded as less binding.

We must attempt vigorously to perceive zoning as not being limited only to urban land and land with buildings on it, but as being applicable to activities more generally, both on land and on water. In cottage regions where recreation pursuits take place on locally adjacent land and water areas, zoning 
efficient to disperse employment centres over the entire urban area and to stagger working schedules daily, weekly, and even on a seasonal and an annual basis. ${ }^{1}$ Many employees now have tasks that can more easily be performed at home, and the work, rather than the worker, transmitted to the employer. The expense of a transportation system to shuttle large numbers of people between home and work, and home and recreation, may be far greater than the expense of large-scale conversions to altogether new employment and residence concepts.

Society is at the threshold of what may be called a time revolution. Over the next generation or two, concepts of time, the division, allocation, rationing, saving, making, and wasting of time will be revolutionalized. The most successful people in the future will be those who can best adjust themselves to radically new time budgets, measured on a scale from the day to the lifetime. Much of the malaise of urban life, especially the dissatisfaction and anomie of workers, ${ }^{12}$ can be attributed to dysfunctional time attitudes. We try to do too much in too short a time, yet we also waste an inordinate amount of time with largely inefficient or unnecessary activ- ity. It may be profitable to eliminate from our work and recreation those activities for which there is no time, and those activities which waste time. We can purchase far more recreation paraphernalia than we can ever hope to have time to use; we must learn to ration.

How will the time-revolution affect the culture of cottaging? It is quite feasible that someone building a cottage today, intended for weekend and vacation use, will, within his lifetime, live permanently in a recreation residence and commute to a secondary work-oriented residence in a city (or even several cities), according to a time scale and schedule of employment that is at present unpredictable.

Should such luxuries, available to a few, be socially tolerated before permanent housing for everyone has progressed to an adequate minimum level? How must urban and regional planning today adapt in anticipation of such lifestyles tomorrow?

Within these futuristic vistas, the concept of a cottage, and the need for a cottage policy, merge with the goals of long range environmental planning in Ontario. Such goals, if ever formulated, would form the philosophical foundation for a cottage can play a key function to orchestrate the grand scenario of recreation activities. For example, motor-boating and other on-water activities with which it conflicts should be spatially or temporally separated. ${ }^{8}$ On the shoreline, intensive development for cottaging must be distinguished from undeveloped back-land and forested hinterland, and especially from areas with wildlife or wilderness qualities.

Zoning is not a stationary concept, but is dynamic and adaptable. In its implementation in planning, it must be adjusted to reflect evolving new circumstances. Yet, at present in Ontario, the flexibility of zoning (both its greatest asset and its worst enemy) is being abused. The real role of zoning is frequently misunderstood, due to a popular misconception that the purpose of zoning, as stated in by-laws and in legislation, is the same as its role in practice. In fact, the hidden intent of zoning legislation is to use zoning as the bait to invite developers to apply for by-law amendments, and then to use the amendment procedure as an opportunity for the municipality to negotiate for development control. That is, a municipality bargains for development control by rewarding the developer with a promised zoning by-law amendment.

Clearly, what is needed is efficient development control on its own charter. Established land use zones should be respected and should not be changed to meet irrational pressures originating from the market mechanism. If properly used, zoning is a useful planning instrument, particularly in areas of stability and little or gradual change, and especially as a reflector and a sensor of local interests.

\section{6/ Administration}

Ultimately, provincial policy has to be implemented at the level of local and regional government. A chasm exists between policy discussed by officials in the central government, physically and psychologically removed from the day-to-day local scene of practical problems, and regional and local officials struggling in a little appreciated, financially inadequate, and often antiquated system. Establishment of a theoretical best provincial cottage policy is meaningless, if it cannot be implemented effectively. A cottage policy therefore would have to evolve hand-in-hand with impartial and unpartisan improvement of the whole basis of cottage development-control, planning, and administration by local and regional levels of government.

There is an on-going move in Ontario to decentralize planning from the provincial level to the level of local and regional councils. Decentralized government that is closer and more accessible to the people is good, provided that the process of decentralization does not splinter province-wide policies into conflicting regional variations. ${ }^{9}$ Therefore, any changes in local and regional cottage planning must mesh into the larger framework of a cottage policy for the province as a whole.

As a lesson for Ontario, in Swedeı, for example, local government units were re-organized into larger regional municipalities, called kommun, and given increased planning powers, a process that is quite similar to the development of regional municipalities in Ontario. ${ }^{4}$ With carefully developed guidelines, standards, and technical assistance from the central government in Stockholm (mostly from K-Konsult, an independent, pseudo-government, non-profit consulting organization that provides planning assistance at cost to any kommun that requests it), each kommun develops a plan for its region.
Significantly however, while these plans show a wide latitude of adaptation to local conditions, they must also adhere to a nationwide "physical plan" being formulated for Sweden's development. Ontario could well use a province-wide "physical-plan" as a master blueprint for the various emerging plans being developed by the new regional municipalities.

\section{7/ Public rights}

The terms-of-reference for an Ontario cottage policy should not be limited only to the cottage owning public. The underlying philosophy must be that a sound provincial cottage policy will benefit not only cottage owners, but non-owners as well.

Water is a natural resource owned in common by all of society, and its rightful use in lakes and rivers, or in whatever way, by all people, is a fundamental premise in resource planning. Use by one group must not exclude or hinder use by other groups. The nonresident public and riparian owners have an equal right to use the water in a lake surrounded by private cottages. Creating a situation of shoreline development and riparian land tenure which prevents the public from exercising this right is immoral. However, protection of public rights, and protection of the rights of private cottage owners, should not be looked upon as being mutually exclusive or contradictory goals. With good design, zoning, and efficient administration, it is possible to facilitate water and shoreline use by both the seasonally resident cottage population, as well as by nonresidents.

Public access points to the water and facilities for public recreation should be made available at every lake, even if it necessitates the expropriation of some property or the purchase 
policy. At present, Ontario has neither the goals nor a policy.

\section{References}

1. BEST, F. 1973. Flexible work scheduling: beyond the forty-hour impasse, p. 93-99. In F. Best (ed.). The future of work. Prentice-Hall Inc., Engelwood Cliffs, NJ.

2. BLUMENFELD, H. 1965. The modern metropolis. Sci. Amer. $213(3)$ : 64-74.

3. CHARLES, W. H. 1972. Comparative legal approaches to non-resident land tenure. In Shoreland: its use, ownership, access and management. Can. Dep. Environ., Lands Direct. No. 90.

4. CIVILDEPARTMENTED. 1972. Hushållning med Mark och Vatten. Bilagor 2 och 3 till Kungl. Maj:ts proposition $\mathrm{nr} 111$ år 1972, Stockholm.

5. DAKIN, J. 1974. Telecommunications experiments in urban and regional planning. Univ. Toronto Press, Toronto, Ont.
6. GIBSON, D. 1973. Constitutional jurisdiction over environmental management in Canada. Univ. Toronto Law. J. 23: $54-87$.

7. JAAKSON, R. 1970. Planning for the capacity of lakes to accommodate water-oriented recreation. PLAN Can. 10 (3): 29-40.

8. 1971. Zoning to regulate on-water recreation. Land. Econ. XLVII: 382-388.

9. 1972. Decentralized administration and citizen participation in community planning. Long Range Plan. 5:16-22.

10. - 1974. A mosaic-pattern of balanced land-water planning for cottage development. J. Can. Instit. Plan. $14: 40-45$.

11. ONTARIO ECONOMIC COUNCIL. 1973. Subject to approval, a review of municipal planning in Ontario. Ont. Econ. Counc., Toronto, Ont.

12. UDY, S. H. Jr. 1970. Work in traditional and modern society. Prentice-Hall, Inc., Engelwood Cliffs, N.J. of easements. Three items have a high priority on the agenda for an Ontario cottage policy. First, an inventory of existing public access points. Second a plan for new access points. Third, an amendment to the Beds of Navigable Waters Act, or the legislation of an entirely new act (a "Public Beaches Act") to remove the long-standing dispute between private shoreline ownership and public rights of use of the shoreline between the high and the low water mark.

\section{8/ Foreign ownership}

An extension of the principles of public protection encompasses the question of the non-Canadian, mostly American, public. It is important to define what, if any, differentiations exist in the public rights of Canadians and non-Canadians (all others except citizens and landed immigrants). Are special length of residence criteria needed? Should Canadians be given first choice, or other preference, in the selection of cottage sites? In the lease of Ontario Crown Land, the province allows leases to be arranged with nonCanadians only after a one year period has elapsed from the time of notifica. tion, to give Canadian citizens a first choice in the selection of cottage lots. Should non-Canadians be limited to renewable term-leases of cottage land? Should special taxes be levied on nonCanadian cottage owners?

Prince Edward Island has enacted legislation to limit foreign land-ownership, and in Ontario the Economic and Cultural Nationalism Committee is evaluating similar measures. However, under the British North America Act, jurisdiction over aliens and naturalization is a Canadian federal matter. Furthermore, the Canadian Citizenship Act, Section 24, provides aliens with the same property ownership rights as are enjoyed by natural-born citizens, and the Canadian Bill of Rights and various provincial Human Rights Acts have similar clauses. ${ }^{3}$ It is therefore an interesting question whether Ontario, or any other province, has the right to regulate foreign ownership of land. ${ }^{6}$ The above question constitutes a vital research theme, insofar as it relates to the main theme of policy needs for cottage planning in Ontario

\section{9/ Cottage financing}

The social imbalances in the Canadian housing market were alluded to earlier. Research is needed to determine if social inequities are hidden in the existing system of financing cottages through the purchase of mortgages. Do cottage mortgages obtained by the well-to-do remove from mortgage financing sources funds which otherwise could have been used by the less well-to-do to purchase mortgages for primary residences? That is, does cottage financing for the wealthy increase the cost of housing for the poor? If research were to show, for example, that mortgage sources are limited, then socially equalizing objectives may perhaps be achieved by restricting, limiting, rationing, or otherwise controlling mortgages for second residences.

Closely allied to the issue of second residence mortgages is the question of the sale or lease of Ontario Crown
Land. Are the true costs of preparing such land for cottage use reflected by the prices, or are the Ontario taxpayers collectively subsidizing these transactions which benefit a privileged minority? Do socially more beneficial alternate uses exist for Crown Land otherwise designated for cottage development? A clear stand by the province on the question of private cottage development on Crown Land is the prerequisite to any cottage policy.

\section{0/ Cottage renewal}

All cottage subdivisions are not the mirror image of those owned by high income groups; cottage slums exist also. A rustic cottage, located to meld with its surroundings, and with primitive but effective services, is a modest cottage, not a slum. Cottage renewal may be justified by ecological demands (for example, in order to revitalize an ecosystem, some properties may have to be weeded out or controls imposed on activities, appliances, and equipment owned by cottagers), or by virtue of the dilapidation of structures and buildings. Most often the two reasons will be found together. Renewal and rehabilitation of derelict neighbourhoods in cities have existed for some time, but similar remedies in older cottage areas, some of which may have acquired urban attributes, are relatively rare. Renewal and rehabilitation traditionally have focused primarily on the physical man-made condition of the environment; renewal and rehabilitation justified by ecological reasons are still largely unknown. 